
\title{
ZS Research Square \\ How do older women perceive their safety in urban outdoor environments?
}

\author{
Azadeh Lak ( $\nabla$ a_lak@sbu.ac.ir) \\ https://orcid.org/0000-0001-8475-1781 \\ Reihaneh Aghamolaei \\ University of Tehran https://orcid.org/0000-0002-5655-100X \\ Phyo K Myint \\ University of Aberdeen
}

Research

Keywords: Perceived Safety, Older Women, Urban Open Spaces, Active Aging

Posted Date: February 20th, 2020

DOI: https://doi.org/10.21203/rs.2.24088/v1

License: (1) This work is licensed under a Creative Commons Attribution 4.0 International License.

Read Full License 


\section{Abstract}

Backgrounds

According to the elders' health as the main priority of Ageing in place, recent research focuses on better understanding of the elders' needs of perceived safety especially the elder women as the vulnerable group in urban open environments. The aim of this study is to explore the perception of elder women about safety and its related features in outdoor spaces according to promoting active ageing.

Methodology

We carried out a mixed-method study in which the data collection was conducted through content analysis. Semi-structured interviews were held with 54 older women (mean age 78.40 years). The participants were recruited in open spaces of Tehran applying the purposeful sampling and continued saturation during summer and fall of 2018. All interviews were recorded and transcribed verbatim. The qualitative content analysis was used to extract sub-themes and main themes. In order to prioritize the extracted concepts, analytic hierarchy process was applied in quantitative analysis (AHP) in quantitative phase.

Findings

According to findings, the perception of safety in female elders can be described in three main themes consisting of psychological, functional and environmental safety, in that order of priority. Psychological safety includes fears of falling, getting lost, social limitation, anxiety, and social support or capital while functional safety consists of fears of public transportation, walkability, and physical activity. Finally, environmental safety comprises of fear of road traffic accidence, criminals, upkeep, incivility, and nuisance.

Conclusion

Our findings provide both personal and environmental features that can be targeted and requires implementation from policymakers and urban developers to meet the needs of growing older vulnerable population to achieve global active ageing goals.

\section{Introduction}

Environmental gerontology has focused on the outdoor environment as one of its major attributes of older persons' needs within the area of urban design studies [1]. Outdoor environments have been recognized as having a positive influence on physical activities [2]. Indeed, physical activity is an important healthy lifestyle behavior associated with maximum physical potential, and healthy living while ameliorating the effects of age such as a decline in physical functioning and impact of co-morbid chronic conditions [3]. It also provides older people with socializing opportunities, promotes independence and improves their quality of life [4], health and social outcomes [5, 6]. 
The benefits extend beyond physical health; there is strong evidence to support urban open spaces reduce stress and fatigue [6-9], improve community interactions, as well as has positive influence on emotional health $[4,10]$. In addition to, the safe and aesthetic places are important factors for users in an outdoor environment [1], to be associated with positive impacts such as healthy behaviours [11-13].

Since older people are vulnerable to environmental qualities of outdoor spaces, there is a rapidly growing interest in the concept of age-friendly urban environments worldwide [14]. Literature suggests that the barrier-free design of urban facilities are a great help to the elders in order to use safe urban places [15]. The previous studies reported the importance of giving attention to promotion and frailty prevention for older women. There is considerable evidence that women report higher threats to perceived safety than men, and that this may be due to gender differences between women and men in the fear of crime and perceived safety[16]. Accordingly, what accounts for gender differences in perceived safety? Why women are claimed as frailer than men despite living longer?

Women are usually regarded as a vulnerable group in society $[17,18]$. According to Schroder-Butterfill and Marianti (2006) the vulnerability for a women is defined as "a person's risk of suffering harm - her vulnerability - is the incremental outcome of a set of distinct but related risks, namely: the risk of being exposed to a threat, the risk of a threat materializing, and the risk of lacking the defenses to deal with a threat" [19]. Due to their fear of being a victim, older women express a more emotionally charged reaction to crime compared to older men who tend to hide their fear [20]. As, the mental image of women in urban spaces is established around two key concepts of a sense of security and fear of space, which can affect women's mobility and presence in outdoor spaces [21].

In fact, many studies have reported gender differences in the perceived safety of urban open spaces. Compared to men, women's experience of outdoor spaces is more often with worries of personal safety $[22,23]$. Women often report levels of fear of crime that are two to three times higher than men's. So, fear of crime imposes limitations upon women's daily lives [24]. Also, older women suffer from "disproportionate anxiety", i.e. crime statistics show that their risk of being a victim is no more than any other group at other ages, however, their fear is "real and pervasive" and "time and place specific" [20]. Therefore, older women are less likely to participate in open spaces [25]. This is perhaps why while there is a small number of officially reported victims and disaggregated data, there is little knowledge about the experience of crime and perceived safety among older women [26].

Women's perception of urban environments has not received enough attention in urban planning research. In addition to this, research in developing countries never attracted that much attention to the older people, especially senior women which created evidence gaps in environmental gerontology. Therefore, it is important to have a clear knowledge of facilitators and barriers specific to older women which can be used for long term behavioural change to promote their physical activity [4].

We aim to provide an understanding of the older peoples' views of preferences for urban open spaces while analysing the older women's perception of the environmental barriers for their physical activity. In addition to filling the evidence gaps, the findings will also be useful to develop a conceptual framework 
eventually to identify the most important domains for future urban planning and resource allocation to promote healthy lifestyle behaviours for older women.

As stated in the European Declaration of Urban Rights, safety and crime prevention is beyond the necessity; it is a right for urban residents by living in a secure and safe places, apart from crime, delinquency and aggression by reducing fear of crime and crime rates [24].

In Iran, there are a few studies, mainly qualitative, related to experiences of perceived safety perceptions among elderly people particularly female elders. Due to the fast growing elderly population in Iran, understanding the features that contribute to experience safety of this special needs group is crucially important [27]. On the other hand, by increasing the awareness about the perceived safety of the female elderly to be more present in outdoor spaces, improving their quality of life could be a positive development for health policy makers. Furthermore, because this is a complex, subjective, contextual, and cultural bond issue that has not been well studied, this study aims to qualitatively explore perceived safety and its contributing factors based on the women older adults' perceptions and experiences to provide better situation for active ageing and ageing in place.

\section{Methodology}

This is a mixed-method study to understand and prioritize the older women's perceived sense of safety from the View of female elders regarding the urban open spaces' features. The research is done in two comprehensive phases: 1) a qualitative process for extracting the substantial concepts, subthemes, and themes on older women's perception of safety in their lived experiences in outdoor spaces through semistructured interviews and content analysis, and 2) a quantitative process using Analytic Hierarchy Process (AHP) methodology where these factors are weighted and prioritized while taking into account of their importance. The process is summarized in Fig. 1.

\section{Qualitative Phase: Content Analysis}

Qualitative content analysis is conducted in the first phase in order to provide a comprehensive description of this issue as a result of which $t$ can be extracted to describe the phenomenon [28]. Based on this principle, data were gathered from participants without prior assumptions. The major advantages of this method are the fact that the gathered data describe the phenomenon as perceived by the participants based on their personal experience (Corbin\& Strauss, 2008).

\section{Participants and Sampling}

Purposeful sampling was chosen as it is suitable for studying broad issues with several aspects that require to be covered and allows data collection from diverse perspectives [28]. The basic inclusion criterion for this research was the older women's perspective about safety in urban open spaces in the urban open spaces of Tehran. Participants were selected through purposive sampling from stakeholders who were active in community centres regarding their experiences of being active present in outdoor 
spaces in Tehran's' urban spaces. Selection of study groups was based on the objective of the study, and in light of the research question, study samples included active female elders in their neighbourhood spaces. Thus, 54 older women -aged over 65 years old were recruited in this study. The inclusion criterion for female elderly participants was having a history of visiting the open spaces more than three times a week in order to walk and hang out with friends. In order to provide a comprehensive picture, different groups of socio-demographic status (e.g. education, marital status, and occupation) were included in the study.

All study participants were residents of Tehran, consented to participation, had favorable communication skills, and were interested in sharing their experiences. The endpoint for sample selection was reaching data saturation regarding perceived safety. At this point, additional information obtained from the 5 final interviews did not vary the categorizations.

\section{Data collection}

Semi-structured interviews were conducted from June to September 2018 as the main method for data collection. These interviews started with general questions and continued with more details questioning (Table 1). The main goal of these questions was to explore the respondents' experience of a sense of safety in urban open spaces in specific situations using open questions, for example, the question "In the face of these issues what did you do?" was asked to identify their reaction in an unsafe situation.

Table 1

The semi-structured questions in the qualitative phase

\section{- In which place you feel safe? Why?}

- In which place you feel unsafety? Why?

-When do you feel safe in urban open spaces? Why?

- In the face of these Issues, what did you do?

- What issues or concerns did you face while you experience safety and unsafety in urban open spaces?

- What happened to you before feeling unsafety?

- Explain about some examples of how you experienced unsafety in urban open spaces?

- Can you explain how you perceive safety in urban open space?

- When do you feel unsafety in urban open spaces? Why?

The interviews usually lasted for 20-40 minutes and carried out at a time and place mutually agreed by the interviewer and the participant and usually at the place of participants' convenience. Also, 20 women of former participants were included in a focus group discussion (FGD) in October 2018 at the Tehran city council of older women. The goal of conducting FGD was not only to ensure reaching saturation with 
certainty but also to validate the gathered data through a focus group. The participants also weighted the factors in the discussion held on November 2018. Furthermore, field notes were also included in data collection and analysis in order to complement the data and their validation.

\section{Data Analysis}

The interviews were first recorded, then transcribed and later validated through the comparison of the text and the recorded file. Also, the final text was reviewed for a few times to provide the researchers with complete familiarity with the information. Then, the meaning units were extracted in the form of words, sentences, or paragraphs including related aspects in their context and content. Researchers continued extracting concepts until they reached a full description for each aspect of the research question or data saturation.

After each interview, audio files were listened to several times and verbatim transcriptions were prepared. Each entire interview was considered as an analysis unit. The transcribed script was read several times to become familiar with the context, after which, the meaning units were identified. The meaning units were then condensed according to their content and context. The data provided the end of this process were labeled and marked with related meaning units and concepts. Next, themes and sub-themes were derived based on the shared and different points of characteristics and aspects of the analyzed concepts to provide the themes and sub-themes with internal homogeneity and external heterogeneity which could be eventually appropriate for presenting the content (Table 4).

\section{Rigor}

In order to elevate the trustworthiness and credibility of the data the following methods were applied:

- Researchers were engaged with the process of data collection while being informed about the cultural profile and living conditions of the participants.

- The data were checked by a peer expert (peer check).

- The participants checked and confirmed the researchers' interpretations of the data (Member check) [28].

The Ethical Committee of the Iran University of Medical Sciences approved the study. Participants were allowed to withdraw their participation at any time while their consent was gained for use of their interview being recorded to that point.

\section{Quantitative phase}

This phase was conducted after the content analysis. During this phase, the themes and themes were determined based on older women's perceptions of safety in urban open spaces. Then, the AHP technique was applied in order to define the importance of weighting each theme/sub-theme. 40 participants in FDG were recruited again to weigh ten the criteria.

\section{AHP and Matrix construction}


AHP method was first presented by Thomas Saaty in the 1970s which is fully structured and suitably equipped for organizing the decisions and analysing them based on the mathematical and psychological insights [30]. One of the most important characteristics of this approach is to present the individual preferences in the form of scale weights which provides the researchers with the possibility to compare and rank different aspects of a decision. This method has been applied in different realms of domains including urban planning, fire risk analysis, engineering decision making, project selection, evaluation and management, housing, banking and marketing [31].

The key characteristics of the AHP method are the hierarchical structure of complexity, pair-wise comparisons, unneeded judgments, and as an eigenvector method for providing weights and steadiness considerations [32]. This method provides the decision makers with a model in which a complicated phenomenon is demonstrated with its goal at the top of the model and its criteria, sub-criteria (factors) and alternatives portrayed in a drop-down way [33].

In this study, the AHP method considers the two elements of sub-themes and themes. The FGDs' participants were provided with a table which included 9 levels of paired-comparisons [30]. A paired comparison would result in a numerical value that corresponds to the biggest eigenvalue of the matrix representing, in turn, the level of importance for each criterion [34]. The first step was creating a hierarchical tree including the sub-themes and themes for executing hierarchical analysis (Fig. 1). The next step was putting the sub-themes previously derived from the qualitative phase into the paircomparison matrix so it could be possible to weight each of them. Then, the evaluated weights were assigned by the members of FGD. The members were asked to weigh based on their thoughts, concerns, attitudes, and experiences regarding the issue in a complete and individualistic sense [35].

In order to avoid possible inconsistencies, the calculation process was done according to Expert Choice software [35]. Then, geometric mean was used to combine the comparative tables of each respondent after putting the derived indicators into the checklist $[36,37]$. At the final phase, the matrix provided the overall mean, measurements and analyses which were used as raw data into Expert Choice software.

\section{Results}

\section{Qualitative phase: Content analysis Participants and Sampling}

The mean age of 54 participants was 78.40 years (range $65.00-82.24$ ), $43 \%$ widow (Table 2). The principles of data saturation were used as the base for determining the number of women. In this method, the purposeful sampling continues until the authors hit the saturation point in any concepts and further data collection would not provide any new concept. 
Table 2

Demographic characteristics of participants

\begin{tabular}{|c|c|c|}
\hline \multicolumn{2}{|c|}{ Demographic Indicators } & \multirow{2}{*}{$\begin{array}{l}\text { The number (Percentage) } \\
19(35.7 \%)\end{array}$} \\
\hline Age & $65-75$ years old & \\
\hline & $75-85$ years old & $19(35.7 \%)$ \\
\hline & 85 years old and over & $16(29.6 \%)$ \\
\hline \multirow[t]{2}{*}{ Marital status } & Married & $30(57.2 \%)$ \\
\hline & Widow & $24(42.8 \%)$ \\
\hline \multirow[t]{3}{*}{ Education } & Illiterate & $20(38 \%)$ \\
\hline & Elementary/high school & $16(28.6 \%)$ \\
\hline & graduate & $18(33.4 \%)$ \\
\hline \multirow[t]{3}{*}{ Occupational status } & Unemployed & $16(29.6 \%)$ \\
\hline & Employed/retied & $19(35.7 \%)$ \\
\hline & Housewives & 19 (35.7\%) \\
\hline
\end{tabular}

In next step, among these 54 participants, 40 older women $\geq 75$ with wide socio-demographic status were recruited randomly in two sections of FGDs, not only to validate the trustworthiness of extracted concepts but also to weight the extracted sub-themes and themes according to their perspective about the perception of safety in urban open spaces.

\section{Data analysis}

After coding, the results indicate the sub-themes and themes as derived and classified according to the major concepts, their shared features as well as their differences. After extracting the concepts through contextual data, the indicators were carefully analyzed. Respondents' experiences and responses were classified into three major themes of safety: environmental, functional and psychological/personal in urban open spaces (Table 3). 
Table 3

Themes and sub-themes and percentage of answering

\begin{tabular}{|llll|}
\hline Theme & Sub- themes & $\begin{array}{l}\text { Frequency of answering } \\
(\mathbf{N}=\mathbf{5 4})\end{array}$ & $\begin{array}{l}\text { Percentage of } \\
\text { answering (N } \\
\mathbf{5}\end{array}$ \\
\hline Environmental Safety
\end{tabular}

\section{- Environmental Safety}

The participants' perception of environmental safety includes car crashes, crimes, incivility, nuisance, and lack of upkeep.

Due to crashes, the car crash is one of the major determinants mentioned by older women as the cause of feeling unsafety and fear in outdoor spaces. This fear roots in their feeling of vulnerability resulted from fast driving, traffic volume, accidents, and dangers while crossing the streets. Also, traffic volume and high-speed driving lead to women's anxiety and stress while crossing the streets.

"Always, when I leave the house, I am scared of fast cars hitting me and breaking my arms or legs. Then I will be unable to leave the house ever again and die like that. Crossroads, cars, and motorcycles scare me. I feel unsafe all the time and have to be constantly careful" (Participant ID. 1016, a 65-year-old woman). 
Besides, crime and criminals are mentioned several times by the older women who find themselves helpless and weak when confronting criminals. They complained mostly about drug smugglers, robbers, and the lack of surveillance in urban open spaces. The prevalence of drug addiction and drug smuggling in urban areas, especially in parks, besides theft and robbery are among the components causing fear for older women.

"Once a robber robbed my friend, took her purse, and hit her on the ground. Her head hit the asphalt. I don't want this happen to me. The problem is why here is unsafety in the first place. It's a social problem. He robs because he needs money but I'm old and I might be hurt". ... "I am scared of being kidnapped by stranger cars, especially when it's dark outside." (Participant ID. 1020, a 72-year-old woman). 
Table 4- The extracting of meaning unit, codes, sub themes, and themes of perceived safety among old women

\section{Themes Sub- themes Concepts Meaning Unit}

Crashes

- Traffic Speed

- Traffic volume

- Having an accident with the car for high speed

- Traffic accident

- Crossing street

- Having a sense of traffic jam

- Leg Brocken for the accident

- Fear of passing street and injunctions

- cars and motorcycles

Crime

- Robbery

- No Surveillance/No police

- Drug smugglers

- Strangers

Incivility

- Assault

- Harassment

- Graffiti

- Litter and trash

- Violence

- The youth presence

Nuisance

- Dense

planting/trees - baggers insistence for charity

- Baggers presences

No upkeep

- Well

- Well Upkeep Upkeep/control
Fear of physical activity
- Visibility

- Mixed use

- Lighting

- Accessibility

- Vibrant activities

- Slope

- Sidewalk design

- Curb design

- Vacant space/deserted
- Fear of theft bags

- presence of police

- drugs and criminal activities in parks-

- being annoyed of the youth assault

- not happy for graffiti and vandalism

- unsanitary for trash and litter-

-The youth violence in outdoors

- shouting in the street

- planting and trees
- having visual visibility to places

- variety of activities and people

- sufficient lighting in night

- easy to go and entrance

- no dark or concealed areas

- having active frontage and full of people - adequate slope 
- the slippery surface in winter Non-slippery, even paving surfaces

- Flat or gently sloped paths

- deficient pavement

- geometric design to walk easily

- not deserted space for crime activities

Fear of Public Transportation

- The bus station and the metro stop

- Empty Parking

- feeling unsafe in the metro station

- a hiding place for criminal activities in an empty parking

- fearful of modes of transport other than the car

- feeling unsafe for inadequate slope and slippery surface

- non- geometric place

- Slope

- Curb

- pavement

- Loneliness

- Depression

- Crowdedness

- Sense of unhealth

- Darkness
Fear of

anxiety -fear of being alone in places

- feeling no enthusiastic to be in outdoor

- feeling unhappy for a crowd of people in parks

- isolated and unused or poorly maintained

- potential perpetrators; it also makes things feel comfortable for someone who might have anxiety or fear"

Fear of getting lost

- Signage

- Wayfinding/ orientation

- finding the right way by adequate signs

- being familiar to find the ways in neighborhoods

-a sense of orientation and a good grasp of the surroundings

Fear of physical

disability
- Physical limitation

- U Distance

- No Restroom

No social capital
- No Social support

- No trust
- fear of losing energy to walk outsides

- fear of long distance to find the restrooms and shops

- feeling safe and relax for social and people help

- being with others

-no quality of life (Health services/ insurance/ pension) 
In addition, urban incivility such as -fights and knife attacks, the roaming of young men and boys in the streets and pathways- all affect the quality of older women in open urban open space settings. The most important problem that commonly causes insecurity in urban open spaces is the fear of being sexually abused and harassed in both violent forms of sexual assault and non-violent forms such as shoving, catcalling, and chasing women by men in empty alleys.

Participant ID. 1023, a 67-year-old housewife holding a bachelors' degree said:

"It happens all the time. It has happened a lot to me that a man chased me until I reached my destination, many catcalled me, many stared at me, I have got used to all these. Many men just cannot stop catcalling you when you pass by". "I really get annoyed when I walk in my neighborhood, there are motorcyclists who just pass by really fast and catcall you".

Nuisance is claimed by presence of vendors and beggars in urban open spaces. It also has an impact on the perceived comfort and security for participation and activity in urban settings for older women. Participant ID.1017, a 69-year-old retired teacher said:

"I'm so annoyed by the beggars in the park. I'm afraid they are going to take something out of my purse, but I do not like to think so. I prefer not to go outside".

Buses are also considered as the cause of fear as they are dangerous vehicles for pedestrians in the streets.

According to the participant's view, upkeep is experienced as the sense of control and maintenance of space by maintaining the cleanliness of the place and the sense of keeping the space alive improve the sense of security in older women. Also, a clean environment attracts female groups, older women in particular, which makes them feel safe.

"When I am in an uncared place I feel anxious and stressed. I prefer not to go to these places" (Participant ID. 1018, a 70-year-old woman).

\section{- Functional safety}

Functional safety is another important theme extracted from interviews with regard to older women's walkability and physical activity as well as their fear of public transportation because of Agoraphobia.

Fear of physical activity as on the substantial sub-theme to help participants to be more active in outdoor space is defined by the low level of security in the built environment has led such places to ruined and abandoned spaces that are perceived as unsafe. According to the interviews, the lighting of the urban spaces, the presence of police, mixed-use by accessibility to different amenities, visibility and the possibility of being seen in the spaces, and the installation of surveillance cameras can increase the sense of security urban open spaces. 
Some participants said they used to look for safe and comfort paths to walk which has certain qualities such as visibility, mixed-use, accessibility to amenities and public facilities, vibrant activities and active frontage, good pavement without slope and slippery surface, good sidewalk design, good curb design and absence of vacant space/deserted space.

In urban spaces, urban furniture, roads, streets, and sidewalks are generally designed to fit young men. Most women mentioned physical problems such as holes and dents, slippery surfaces, high stairs, long distance between bridges on water channels, pedestrian bridges, and stairless metro stations, as well as inappropriate metal bridges on the water channels. These issues have made women face more difficulties than men.

One participant suffered from knee and back pain said:

"Some paths are not suitable for pedestrians, pedestrian bridges are not comfortable, if they all have an escalator, it's going to be okay but I often cross the highway because I cannot walk up the stairs" (Participant ID.1012, a 69-year-old retired woman).

Participants are mentioned the fear of public transportation as one of the preventing points of being active in urban open spaces. Some of the participants raised concerns about the uncomfortable urban features such as unkempt bus stations, inappropriate public transportation systems such as crowded public transportation, unsafe parking, and metro stations which lead to their preference for staying inside and resultant dependency instead of taking part in outdoor activities.

"Empty metro stations scare me. I cannot walk up the stairs in metro stations since I have back pain. The safety bars in the metro and buses are too high for me. I cannot grab them in case of not finding a seat. These bars are not suitable for an older woman while everybody else grabs them easy. I prefer staying inside" (Participant ID.1018, a 65-year-old retired woman).

In addition, bus stops on top of the hills require physical ability to walk there. The most significant problem of bus/metro stops is the inappropriate location of these stops leading to less tendency to use public transportation. This issue is harder for women who have a limited physical function. This issue is often worsened when they need to walk through long paths in order to get to the stops since there is often no place to sit and rest and this is further influenced by cold weather and slippery paths.

\section{- Psychological safety}

Another theme extracted from the interviews was labelled as psychological or personal safety which consists of five sub-themes: fear of falling, fear of anxiety, fear of getting lost, fear of moving out and losing social network. Also, as mentioned by the participants, this theme appeared to be a major concern to older women.

Fear of falling is one of the key components of psychological safety and one of the major features leading to reduced participation of older women in open spaces. Inadequate walking paths, slopes, and 
curbs are the main causes of this fear. The results suggest that the fear of falling can cause older women helpless and thus it is a challenging barrier preventing older women from engaging in active walking.

"Older women are not able to do anything because of the fall all the time. They are scared of having a leg broken!" (Participant ID.1011, a 75-year-old household woman).

Fear of anxiety is indicated as one of the prevailing experience among participants in outdoor spaces. Many participants believe that their use of open urban open spaces is affected by the feeling of anxiety and the fear caused by such anxiety, which was expressed as loneliness, depression, crowdedness, sense of unhealthiness and darkness.

"The feeling of fear and unsafety for women is overwhelming and creates many obstacles and limitations. I had a lot of things to do, but because of that feeling of fear, I let them go. Because of this feeling of unsafety, women cannot really improve with their potentials" (Participant ID.1010, a 70-year-old household woman).

Due to fear of getting lost, many participating older women acknowledged that at times they did not even remember their name, forget their home address and even lose their sense of orientation in familiar places. They are less likely to be outdoors due to their fear of having this situation in out-of-home spaces.

"Before, sometimes I would go to the park to deal with my loneliness. I would go to the market. I would visit my relatives' house. But once when I was on my way home I got lost. Since then my children do not leave me alone, they said they will take me where I want to go, but they do not have time." (Participant ID.1028, a 70-year-old household woman).

Fear of physical disability is claimed as one of the crucial fear among participants not to control the situation to avoid more disturbs. Also, personal and psychological barriers create limitations for older women. The limitations on personal performance for this group could be decreased by providing solutions for the long paths and the lack of restrooms in open spaces. Observations showed that older women's experiences and perceptions of urban open spaces are seemingly different from those of others. They may face physical barriers in order to cope with urgent situations including the need for a restroom and physical barrier like a slope.

Due to no social capital, it is indicated as one of the important concepts extracted was the sense of alienation and lack of trust in society besides no social help and interaction among participants to make them afraid in open spaces. It reduces their attention and increases the sense of isolation from others.

"Everyone is just thinking about their own lives having their own stuff, but sometimes I think that I'd forgotten and they do not have enough time for me... Many things have changed. We used to make time for people around us. Life has increased the distance between people, I look around, there is no one, and I am alone. It makes me sad as if we have all become strangers. "(Participant ID.1026, a 71-year-old household woman). 
The lack of social support resources and trust provided by family members, friends and neighbours is regarded as one of the reasons for fear outdoor. Lack of essential living needs, lack of special facilities for the elderly, lack of access to health insurance, low medical insurance facilities, lack of free or cheap support services, high cost of health services, lack of family support resources, lack of job opportunities for the elderly, lack of easy access to subsidized food and appropriate transportation services were identified by the participants as a subset of the lack of support resources.

\section{Quantitative phase}

To prioritize the importance of sub-themes, the weighting of extracted concepts was performed with the help of the FGD participants in this phase. Four major criteria were assessed based on the research goal during the first matrix of comparison. The pair-comparison of sub-criteria is provided in separate groups (Fig. 2).

In addition, Expert Choice software allowed the researchers to simplify the process of decision making. It additionally provided a measure of inconsistency which is useful for discovering the possible errors of judgments. The Expert Choice generates a measure of inconsistency, which is practical for identifying the possible errors of all judgments. The results of a pairwise comparison obtained through the FGD of 40 participants are fed to the Expert Choice software to prevent any inconsistencies in the pair-wise comparison by checking the researchers as the experts [37,38]. The nine-degree Saaty evaluation matrix is used for determining the factors weighted in pairwise comparison [33]. The discussions between the FGD and the Expert Choice led to the results extracted from the pair-comparison (Table 5). 
Table 5

Pairwise comparison scores of the evaluation matrix for AHP results

\begin{tabular}{|llll|}
\hline Main themes & Pairwise comparison & Sub themes & Pairwise comparison \\
scores & scores
\end{tabular}

The results provided by the Expert Choice were standardized from 0 to 10 which facilitated the process of interpretation (Fig. 3). As the level of importance for each subtheme was analysed according to the prioritization of the participants of FGD in this study.

\section{Discussion}

This research has been conducted as one of the first mixed-method studies exploring the Iranian older women's perceived safety in public open spaces and their most important consideration in the senior women's minds, in order to provide design policies to promote their active aging in place. The findings demonstrate the three themes of perceived safety by older women in the order of priority in the order of importance: psychological or personal, functional, and environmental safety. Psychological or personal safety includes the dimensions of fear of falling, fear of anxiety, fear of getting lost, fear of physical disability and no social capital and help. Car crashes, crime, incivility, nuisance, and are the determinants of environmental safety while fear of walkability, physical activity, and fear of public transportation are the components of functional safety. 
Generally, there are two distinct objective and subjective dimensions to explain the theoretical concept of security. The objective dimension is external phenomena, is evaluated by environmental, and behavioral factors (e.g. the rate of crime and criminals like in a community). The subjective dimension is an intrinsic concept that depends largely on the extent to which individuals are aware of crime and insecurity and their interpretation individually [39].

Importantly, psychological safety plays a major role in perceived safety in older women including fear of falling, fear of anxiety, fear of getting lost, fear of physical disability and limitation and having no social capital and trust. Fear of falling includes the person's sense of unsafety during non-dangerous activities; fear of mobility is when the person avoids the activities which are within their physical and functional ability; and fear of functional limitation is when the person deliberately restricts their personal function. Therefore, the older persons' sense of fear increases through their personal experiences such as health and physical vulnerability which leads to the limitation of outdoor activity and the sense of disability [8].

Based on the results, social capital and social network could effectively contribute to older women's sense of safety leading to their increased outdoor activity. The sense of perceived safety in built environments contributes to the residents' participation and interactions with their neighbours $[6,40]$ The level of perceived fear may increase as a result of weak social networks, lack of community cohesion or a generally low level of social capital and the presence of inter-group conflicts which as a result lead to a lower degree of social participation. Social capital and trust are the two concepts related to perceived safety but they are not conceptually and empirically the same [41]. Previous literature has shown that the lack of trust in the neighborhood increases the fear of crime and contributes to the elderly's sense of unsafety $[42,43]$.

Furthermore, older women reported that their perception of functional safety in open space is influenced by visibility, mixed-use, lighting, accessibility, vibrant activities, slope, sidewalk (curb) design, and vacant space/deserted space. Inadequate lighting leads to an increased sense of insecurity which is in line with the previous literature, whilst the feeling of unsafety during the walks in day and night affects the participation in outdoor activities in open spaces [44]. The provision of neighborhood amenities, such as lighting, public facilities, and sidewalk (curb) conditions can shape the walking behaviour of older and promote neighborhood safety [6]. Similar findings are expressed by the participants. Close environmental features like poor surface conditions, slopes/hilliness, and noisy traffic contribute to the fear of outdoor space use and resultant reduced mobility [45]. Improved lighting conditions lead to lower degrees of crime rate due to the surveillance it provides $[42,46]$.

The unsafe bus/metro stations and empty parking lots increase the level of fear and the sense of unsafety among older women. The results of this study reveal that a great number of the attributes causing the fear of public transportation are among those leading to the fear of crime in everyday places. The participants in this study stated that isolated bus stops, unstaffed stations, and pedestrian subways are among the places which increase the level of their fear. Previous reports also highlighted walking in 
parks and subways during the night as well as waiting for the bus in the bus stations or isolated areas were mentioned by the participants as perceived unsafe places $[47,48]$.

Finally, environmental safety through perceived traffic safety was analysed through the assessment of traffic volume and speed along with examples of fast drivers. Nuisance is another attribute that caused fear in older women. The presence of planting has been considered as a crime motivator due to the increased opportunity for criminals to hide. In the neighborhoods prone to criminal activities, residents would relate the dense vegetation with their increased fear of crime [49].

According to the result, upkeep of the urban outdoor environments provides a deeper sense of safety as the women prefer visible social and law enforcement. The higher presence of legitimate visitors increases older women's sense of safety. The participants in this study acknowledged that one of the major causes of unsafe feeling is incivility. Assault is, especially, the most important factor influencing their perceived safety. Also, poor social control and the consideration of incivility and disorder as a norm increases the older person's fear $[42,50]$. Graffiti, litter, and dirt are considered a strong predictor of fear of criminal activities in an open space [42].

This study also demonstrates the relationship between the elderly's health condition and their level of fear since the lack of physical health leads to the older women's feeling of helpless when facing violence [51]. Insurance, pension, and other health services could reduce this fear [6]. Older people who assume they have one or more disabilities are more prone to fear to be a victim of a crime which decreases their outdoor activity [42].

The results reveal that older women have specific needs, thus it is claimed to have programmatic implications to address these needs in the development of community-level interventions for older women to feel safer in urban spaces.

Our study identifies the older women's perceptions of safety in outdoor spaces according to their experiences. This suggests that improvement in environmental qualities may help women feel safer in their communities. In this regard, applying traffic calming policy can help to decrease the traffic hazard at the junction and the chance of accidents. Features of a built environment-such as aesthetic qualityhave been associated with reduced crime. Community surveillance and up-keeping by local authorities represent one possible approach to reducing incivilities and nuisance by improving the elder presence and creating viable opportunities for supportive engagement among local residents [16].As, the former studies in Iran indicated that the females' fear of crime is relatively high in outdoor spaces. This findings are claimed to complete the previous factors such as feelings of powerlessness, social exclusion, weakness of social bonding and self-defense ability affect Iranian women's fear of crime. Furthermore the deterioration of social security, experience of victimization, moral decay in society, social incivility, and social trust could intensify females' sense of fear in urban open spaces $[52,53]$.

The findings attempt to highlight to improve the quality of neighborhood characteristics by providing neighborhood amenities, such as lighting, public facilities, sidewalk condition and pavements, and curb 
design to encourage physical activity level, especially outdoor walking among older women. Moreover, the design of the station platform (subway) and parking lots can influence the elder women's perception of safety to use more public transportation [54]. Making more legible, comfort and high quality built environments would reduce the "fear of falling", "fear of anxiety", "fear of getting lost" and "fear of physical disability" among older women to prevent the symptoms of space phobia [55].

Finally, increasing social capital by participatory interventions aimed at community development may also be effective in improving neighborhood assets such as collective efficacy, not only have been linked to the reduced crime but also help to more social interactions among older women. Aligning perceptions of safety with direct changes in urban open spaces may be a promising approach to addressing feelings of safety and desire for more outdoor walking [56].

By highlighting the different types of perceived safety, including environmental, functional and psychological, when assessing results by gender, researchers and policymakers are more likely to develop a more understanding of the effects of urban open spaces on perceived safety for older women. Future research should also examine whether health and wellbeing are influenced by the varied types of the perceived safety of urban open space among older women.

This study has strengths and limitations. One of the key strengths of the study is the use of the mixedmethod approach and the participation of older women from all walks of life. Through semi-structured interviews with several participants, the richness of the data provides a better understanding of factors that are important for older women with regard to their perceived safety in outdoor open space environments in developing country settings which contributes to the growing knowledge of environmental gerontology. There were also a few limitations to this study. First of all, the purposive sampling was applied which includes the older women with a different background of experiences in different historical, conventional and new town urban open spaces. The results of this study may not be generalized to other societies in which these factors have already been taken into account in their urban open design.

\section{Conclusion}

We have shown that older women are concerned about environmental safety, functional safety and psychological safety in outdoor spaces. Built environment features can also affect older women's physical activity based on their sense of safety. Therefore, policymakers and developers should take these into consideration in creating high quality of urban open spaces which will enhance outdoor activities older women who are a vulnerable group. Considering the concept of psychological safety and its components including social networks, we advise more efforts in order to increase older women's level of participation in urban open spaces. Future research might probe the actual process of active aging based on perceived safety in built environments.

\section{Declarations}




\section{Ethics approval and consent to participate}

This research was approved by the Iran University of Medical Sciences Ethical Review Board (Ethics Code Number; IR.IUMS.REC.1397.148). All participants agreed to be interviewed in this study and verbal consent was obtained.

\section{Consent for publication}

Not applicable.

\section{Availability of data and material}

An anonymized dataset is available by request from corresponding author.

\section{Competing interests}

The authors declare that they have no competing interests.

\section{Funding}

There is no funding in this study.

\section{Authors' contributions}

AL and RA carried out interview and FDG. AL performed all statistical analyses, interpreted the results, and wrote the paper. PKM contributed to interpret the results and revising the paper. All authors read and approved the final manuscript.

\section{Acknowledgements}

Not applicable.

\section{References}

[1] H. Wennberg, J. Phillps, A. Stahl, How older people as pedestrians perceive the outdoor environment - methodological issues derived from studies in two European countries, Ageing Soc. 38 (2018) 24352467. https://doi.org/10.1017/S0144686X17000666.

[2] W.J.S. Soares, A.D. Lopes, E. Nogueira, V. Candido, S.A. de Moraes, M.R. Perracini, Physical Activity Level and Risk of Falling in Community-Dwelling Older Adults: Systematic Review and Meta-Analysis, J. Aging Phys. Act. 27 (2019) 34-43. https://doi.org/10.1123/japa.2017-0413.

[3] S. Bird, W. Kurowski, S. Feldman, C. Browning, R. Lau, H. Radermacher, S. Thomas, J. Sims, The Influence of the Built Environment and Other Factors on the Physical Activity of Older Women from 
Different Ethnic Communities, J. Women Aging. 21 (2009) 33-47. https://doi.org/10.1080/08952840802633669.

[4] M. Annera, S. Keeling, T. Wilkinson, G. Cushman, B. Gidlow, H. HOPKINS, Environmental influences on healthy and active ageing: a systematic review, Ageing Soc. 34 (2014) 590-622. https://doi.org/10.1017/S0144686X1200116X.

[5] L. Frank, J. Kerr, D. Rosenberg, A. King, Healthy Aging and Where You Live: Community Design Relationships With Physical Activity and Body Weight in Older Americans, J. Phys. Act. Heal. 7 (2010) S82-S90. https://doi.org/10.1123/jpah.7.s1.s82.

[6] A. Hong, J.F. Sallis, A.C. King, T.L. Conway, B. Saelens, K.L. Cain, E.H. Fox, L.D. Frank, Linking green space to neighborhood social capital in older adults: The role of perceived safety, Soc. Sci. Med. 207 (2018) 38-45. https://doi.org/10.1016/j.socscimed.2018.04.051.

[7] A. Vaeztavakoli, A. Lak, T. Yigitcanlar, Blue and Green Spaces as Therapeutic Landscapes: Health Effects of Urban Water Canal Areas of Isfahan, Sustainability. 10 (2018) 4010. https://doi.org/10.3390/su10114010.

[8] A. Ruijsbroek, M. Droomers, P.P. Groenewegen, W. Hardyns, K. Stronks, Social safety, self-rated general health and physical activity: changes in area crime, area safety feelings and the role of social cohesion, Health Place. 31 (2015) 39-45.

[9] A. Lak, R. Aghamolaei, H.R. Baradaran, P.K. Myint, Development and validation of elder-friendly urban spaces questionnaire (EFUSQ), BMC Geriatr. 19 (2019) 336. https://doi.org/10.1186/s12877-0191355-0.

[10] J. Maas, R.A. Verheij, S. de Vries, P. Spreeuwenberg, F.G. Schellevis, P.P. Groenewegen, Morbidity is related to a green living environment, J. Epidemiol. Community Heal. 63 (2009) 967-973. https://doi.org/10.1136/jech.2008.079038.

[11] L.D. Frank, E.H. Fox, J.M. Ulmer, J.E. Chapman, S.E. Kershaw, J.F. Sallis, T.L. Conway, E. Cerin, K.L. Cain, M.A. Adams, G.R. Smith, E. Hinckson, S. Mavoa, L.B. Christiansen, A.A.F. Hino, A.A.S. Lopes, J. Schipperijn, International comparison of observation-specific spatial buffers: maximizing the ability to estimate physical activity, Int. J. Health Geogr. 16 (2017) 4. https://doi.org/10.1186/s12942-017-0077-9.

[12] Y. Gong, J. Gallacher, S. Palmer, D. Fone, Neighbourhood green space, physical function and participation in physical activities among elderly men: the Caerphilly Prospective study, Int. J. Behav. Nutr. Phys. Act. 11 (2014) 40. https://doi.org/10.1186/1479-5868-11-40.

[13] H. Weimann, L. Rylander, M.A. van den Bosch, M. Albin, E. Skärbäck, P. Grahn, J. Björk, Perception of safety is a prerequisite for the association between neighbourhood green qualities and physical activity: Results from a cross-sectional study in Sweden, Health Place. 45 (2017) 124-130. 
[14] J.W. Moon, S.K. Jung, Y. Kim, S.H. Han, Comparative study of artificial intelligence-based building thermal control methods - Application of fuzzy, adaptive neuro-fuzzy inference system, and artificial neural network, Appl. Therm. Eng. 31 (2011) 2422-2429. https://doi.org/10.1016/j.applthermaleng.2011.04.006.

[15] M.-M. Lai, S.-Y. Lein, S.-H. Lau, Modeling Age-Friendly Environment, Active Aging, and Social Connectedness in an Emerging Asian Economy, J. Aging Res. 2016 (2016) 1-14. https://doi.org/10.1155/2016/2052380.

[16] E.E. Hoffman, T.T.M. Mair, B.A. Hunter, D.M. Prince, J.K. Tebes, Neighborhood sexual violence moderates women's perceived safety in urban neighborhoods, J. Community Psychol. 46 (2018) 79-94. https://doi.org/10.1002/jcop.21917.

[17] V. Patel, R. Araya, M. De Lima, A. Ludermir, C. Todd, Women, poverty and common mental disorders in four restructuring societies, Soc. Sci. Med. 49 (1999) 1461-1471.

[18] L. Ryser, G. Halseth, Informal Support Networks of Low-Income Senior Women Living Alone: Evidence from Fort St. John, BC, J. Women Aging. 23 (2011) 185-202. https://doi.org/10.1080/08952841.2011.587734.

[19] E. Schroder-Butterfill, R. Marianti, A framework for understanding old-age vulnerabilities, Ageing Soc. 26 (2006) 9-35. https://doi.org/10.1017/S0144686X05004423.

[20] G. Mythen, A critical introduction to the risk society, Cambridge University Press, London, 2004. https://doi.org/10.1017/S0964028205321987.

[21] S.S. Asl, A. Lak, How Safe Is Your Neighborhood? Iranian Women's Perception of Safety and Security, Mediterr. J. Soc. Sci. 8 (2017) 419-430. https://doi.org/10.5901/mjss.2017.v8n1p419.

[22] B. Jiang, C.N.S. Mak, L. Larsen, H. Zhong, Minimizing the gender difference in perceived safety: Comparing the effects of urban back alley interventions, J. Environ. Psychol. 51 (2017) 117-131. https://doi.org/10.1016/j.jenvp.2017.03.012.

[23] E.L. Sweet, S. Ortiz Escalante, Bringing bodies into planning: Visceral methods, fear and gender violence, Urban Stud. 52 (2015) 1826-1845. https://doi.org/10.1177/0042098014541157.

[24] O. Tandogan, B.S. Ilhan, Fear of Crime in Public Spaces: From the View of Women Living in Cities, Procedia Eng. 161 (2016) 2011-2018. https://doi.org/10.1016/j.proeng.2016.08.795.

[25] M. James, P. Mayhew, A. Graycar, A safe and secure environment for older Australians, 2003.

[26] M.A. Blythe, P.C. Wright, A.F. Monk, Little brother: could and should wearable computing technologies be applied to reducing older people?s fear of crime?, Pers. Ubiquitous Comput. 8 (2004) 402-415. https://doi.org/10.1007/s00779-004-0309-4. 
[27] L. Daddoust, H. Khankeh, A. Ebadi, R. Sahaf, M. Nakhaei, A. Asgary, The vulnerability of the Iranian elderly in disasters: Qualitative content analysis, Iran. J. Nurs. Midwifery Res. 23 (2018) 402. https://doi.org/10.4103/ijnmr.IJNMR_127_17.

[28] U.H. Graneheim, B. Lundman, Qualitative content analysis in nursing research: concepts, procedures and measures to achieve trustworthiness, Nurse Educ. Today. 24 (2004) 105-112.

[29] J. Corbin, A. Strauss, others, Basics of qualitative research: Techniques and procedures for developing grounded theory, (2008).

[30] T. Saaty, The Analytical Hierarchical Process. New York, (1980).

[31] R.B. Thapa, Y. Murayama, Drivers of urban growth in the Kathmandu valley, Nepal: Examining the efficacy of the analytic hierarchy process, Appl. Geogr. 30 (2010) 70-83.

[32] G.D. Bhatta, W. Doppler, Farming differentiation in the rural-urban interface of the middle mountains, Nepal: Application of analytic hierarchy process (AHP) modeling, J. Agric. Sci. 2 (2010) 37.

[33] T.L. Saaty, Decision making with the analytic hierarchy process, Int. J. Serv. Sci. 1 (2008) 83-98.

[34] E. Türk, Multi-criteria Decision-Making for Greenways: The Case of Trabzon, Turkey, Plan. Pract. Res. 33 (2018) 326-343.

[35] L. Dahlgren, M. Emmelin, A. Winkvist, Qualitative methodology for international public health, UmeåUniversitet, 2007.

[36] E.H. Forman, T.L. Saaty, M.A. Selly, R. Waldron, Expert choice, Decis. Support Software. McLean, VA. (1983). https://www.expertchoice.com/ (accessed November 29, 2018).

[37] M.S. Ozdemir, Validity and inconsistency in the analytic hierarchy process, Appl. Math. Comput. 161 (2005) 707-720. https://doi.org/10.1016/J.AMC.2003.12.099.

[38] H. Gerçek, B. Karpak, T. Kılınçaslan, A multiple criteria approach for the evaluation of the rail transit networks in Istanbul, Transportation (Amst). 31 (2004) 203-228.

https://doi.org/10.1023/B:PORT.0000016572.41816.d2.

[39] L. Rostami Tabrizi, A. Madanipour, Crime and the city: Domestic burglary and the built environment in Tehran, Habitat Int. 30 (2006) 932-944. https://doi.org/10.1016/j.habitatint.2005.04.007.

[40] F.E. Baum, A.M. Ziersch, G. Zhang, K. Osborne, Do perceived neighbourhood cohesion and safety contribute to neighbourhood differences in health?, Health Place. 15 (2009) 925-934. https://doi.org/10.1016/j.healthplace.2009.02.013.

[41] J. Ladenburg, J.S. Petersen, N.P. Berger, and N.P.B. Ladenburg, Jacob, Jacob Seier Petersen, Perceived safety in socially vulnerable neighbourhoods: A combined multilevel and latent class analysis 
of factors influencing perceived safety, KORA Danish Inst. Local Reg. Gov. Res. Copenhagen K. (2016).

[42] V. Ceccato, R. Bamzar, Elderly Victimization and Fear of Crime in Public Spaces, Int. Crim. Justice Rev. 26 (2016) 115-133. https://doi.org/10.1177/1057567716639096.

[43] L.M. Funk, D.E. Allan, N.L. Chappell, Testing the Relationship Between Involvement and Perceived Neighborhood Safety, Environ. Behav. 39 (2007) 332-351. https://doi.org/10.1177/0013916506290959.

[44] B. Giles-Corti, Socioeconomic Status Differences in Recreational Physical Activity Levels and Real and Perceived Access to a Supportive Physical Environment, Prev. Med. (Baltim). 35 (2002) 601-611. https://doi.org/10.1006/pmed.2002.1115.

[45] M. Rantakokko, M. MÃanty, S. Iwarsson, T. TÃ 9 rmÃakkangas, R. Leinonen, E. Heikkinen, T. Rantanen, Fear of Moving Outdoors and Development of Outdoor Walking Difficulty in Older People, J. Am. Geriatr. Soc. 57 (2009) 634-640. https://doi.org/10.1111/j.1532-5415.2009.02180.x.

[46] K. Painter, The influence of street lighting improvements on crime, fear and pedestrian street use, after dark, Landsc. Urban Plan. 35 (1996) 193-201. https://doi.org/10.1016/0169-2046(96)00311-8.

[47] N. Yavuz, E.W. Welch, Addressing Fear of Crime in Public Space: Gender Differences in Reaction to Safety Measures in Train Transit, Urban Stud. 47 (2010) 2491-2515. https://doi.org/10.1177/0042098009359033.

[48] A. Loukaitou-Sideris, Fear and safety in transit environments from the women's perspective, Secur. J. 27 (2014) 242-256. https://doi.org/10.1057/sj.2014.9.

[49] G.S. Shaffer, L.M. Anderson, Perceptions of the security and attractiveness of urban parking lots, J. Environ. Psychol. 5 (1985) 311-323.

[50] B.R. Wyant, Multilevel Impacts of Perceived Incivilities and Perceptions of Crime Risk on Fear of Crime, J. Res. Crime Delinq. 45 (2008) 39-64. https://doi.org/10.1177/0022427807309440.

[51] L. De Donder, D. Verté, E. Messelis, Fear of crime and elderly people: Key factors that determine fear of crime among elderly people in West Flanders, Ageing Int. 30 (2005) 363-376. https://doi.org/10.1007/s12126-005-1021-z.

[52] S. Sadeghi Fasai, A. Khademi, Narratives of elderly women about living in the modern world, J. Popul. Assoc. Iran. 8 (2013) 123-140.

[53] S. SHAKURIASL, CRIME FRIGHT AMONG WOMEN IN URBAN ENVIRONMENTS: CASE STUDY OF SPECIFIC NEIGHBOURHOODS AND HEALTH, (2016).

[54] C. Majd, Next Stop, Security: Understanding What Makes Women Feel Safe In Public Transportation Stations, (2013). https://ecommons.cornell.edu/handle/1813/33837 (accessed April 25, 2019). 
[55] I. Marks, Space "phobia": a pseudo-agoraphobic syndrome, J. Neurol. Neurosurg. Psychiatry. 44 (1981) 387-91. https://doi.org/10.1136/JNNP.44.5.387.

[56] S.E. Mayer, C. Jencks, F. Earls, Growing Up in Poor Neighborhoods: How Much Does It Matter?, Science (80-. ). 243 (1997) 1441-1445. https://doi.org/10.1126/science.243.4897.1441.

\section{Figures}

\section{Physical Activity Questionnaire Development}

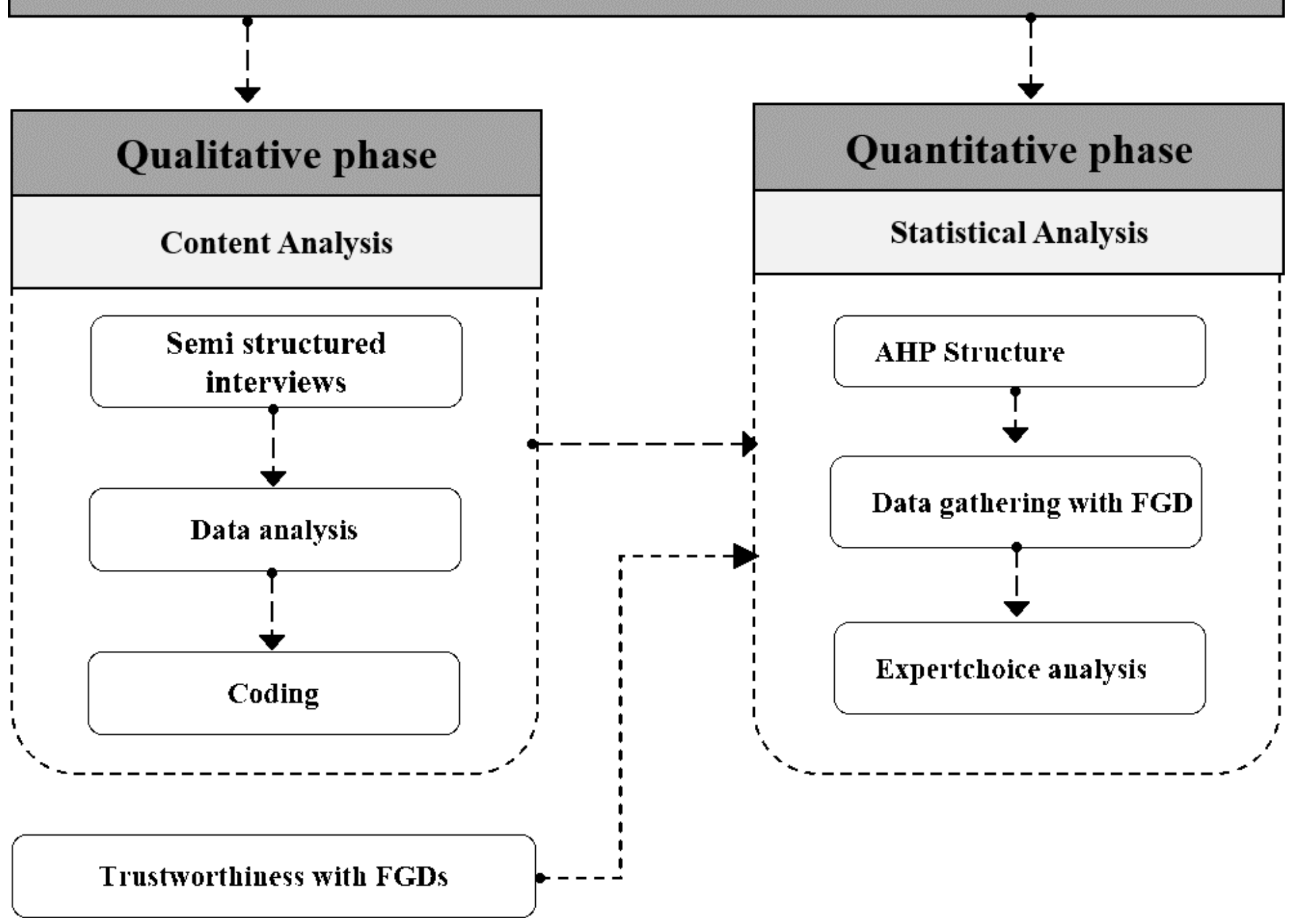

Figure 2

The overarching methodology of research including two main phases of qualitative and quantitative analysis 


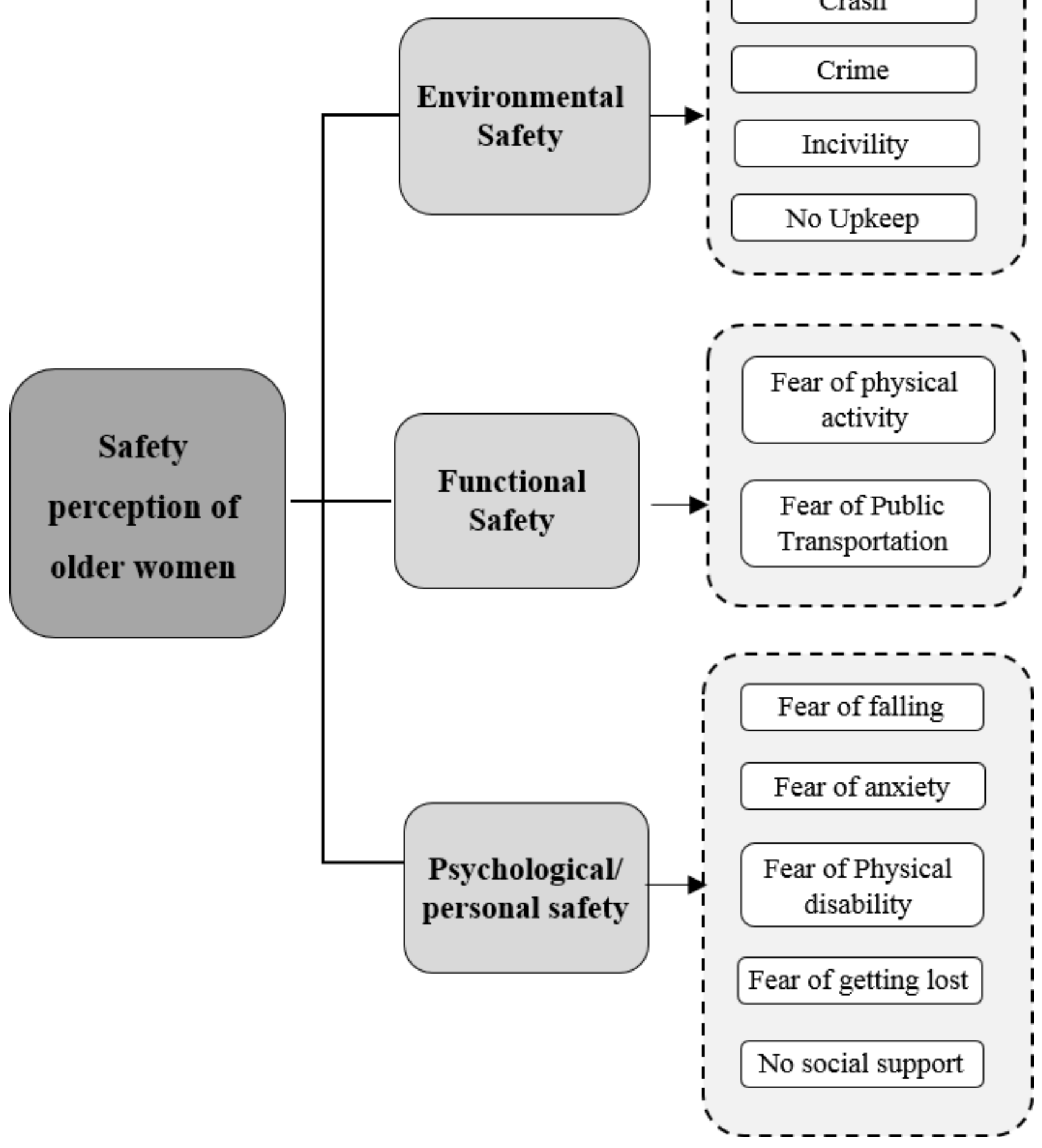

Figure 4

The extracted items of perceived safety in female elders 


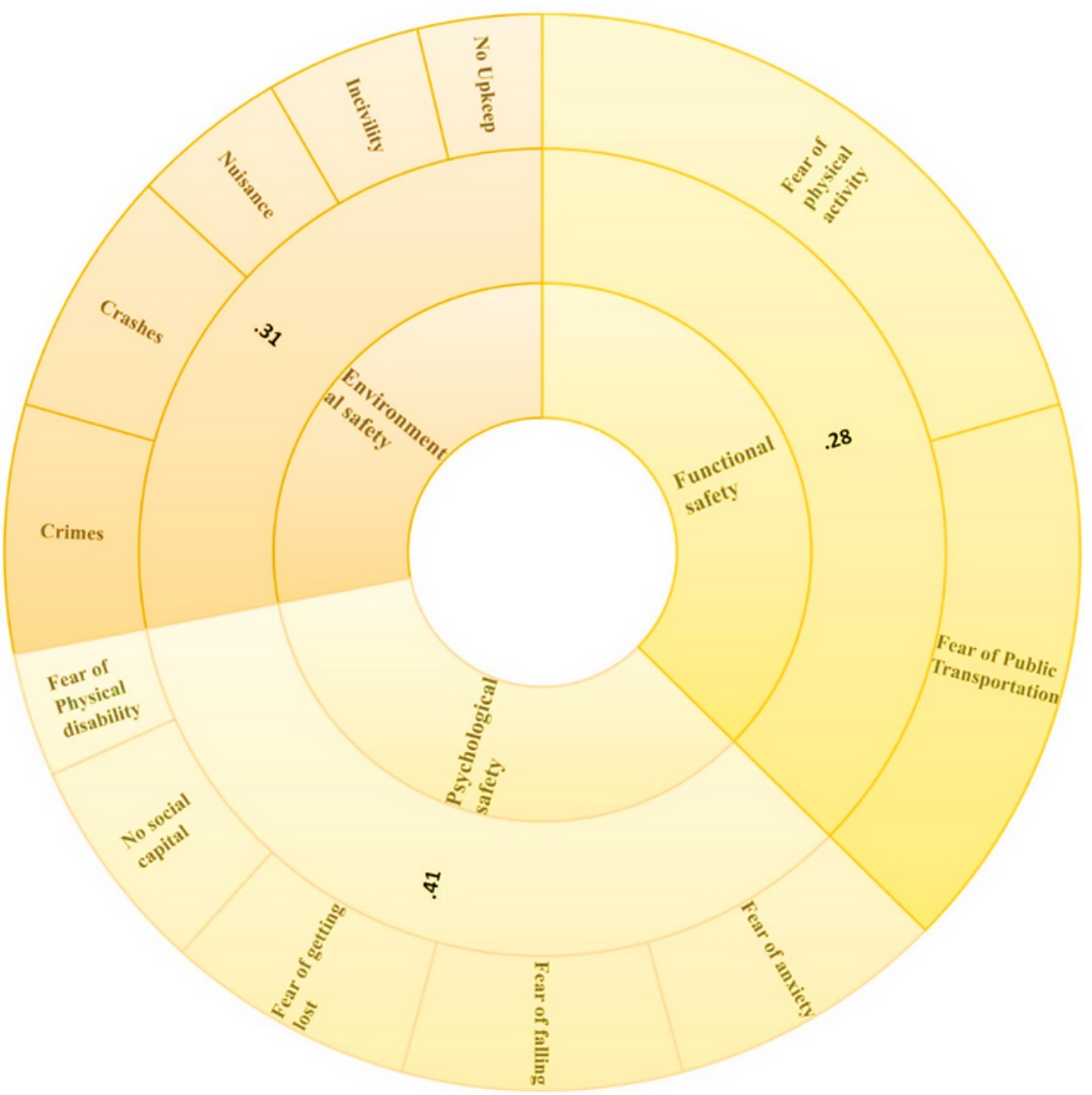

Figure 6

The relative importance of themes and sub-themes s resulted from the AHP process 